\title{
Caracterização morfológica de fruto, semente e plântula de Psidium rufum DC. (Myrtaceae)
}

\author{
Izabele Domingues Soares, Antonio Carlos Nogueira, Jeniffer Grabias \& Yoshiko Saito Kuniyoshi
}

Universidade Federal do Paraná, Departamento de Ciências Florestais, Av. Pref. Lothário Meissner, 632, CEP: 80210-170, Jardim Botânico, Curitiba, Brasil. izabele.soares@gmail.com

Recebido em 12VIII.2015

Aceito em 03.VIII.2017

DOI $10.21826 / 2446-8231201772208$

RESUMO - O objetivo desse estudo foi descrever e ilustrar a morfologia de frutos, sementes e plântulas de Psidium rufum DC. com o propósito de auxiliar nas mais diversas áreas, como a taxonomia e a silvicultura. A espécie é uma frutífera não cultivada, mas com grande potencial ecológico. Para a caracterização das estruturas e descrição das fases de germinação foram utilizadas 100 unidades aleatórias de frutos e sementes provenientes de Curitiba e Ponta Grossa, Paraná. P. rufum apresenta frutos lisos, brilhosos, glabros, de cor vermelho-arroxeado quando maduros, de forma globosa, carnosos e indeiscentes tipo bacoide. As sementes são campilótropas, reniformes, com tegumento liso, opaco e pétreo, apresentam um possível tecido endospermático oleaginoso de coloração creme. O embrião é do tipo pimentoide e a germinação é epígea fanerocotiledonar, iniciando no $15^{\circ}$ dia e estendendo-se até o $37^{\circ}$ dia. As características morfológicas apresentadas são informações úteis para auxiliar no reconhecimento de $P$. rufum.

Palavras-chave: Araçá-roxo, germinação epígea fanerocotiledonar, sementes

\begin{abstract}
Morphological characterization of fruits, seeds and stages of germination of Psidium rufum DC. (Myrtaceae). The objective of this study was to describe and illustrate the morphology of fruits, seeds and seedlings of Psidium rufum DC. in order to assist different disciplines, such as taxonomy and forestry. The species is a fruit that is not cultivated, but has great ecological potential. For structure characterization and germination stage descriptions, 100 units of random fruits and seeds of Curitiba and Ponta Grossa, Paraná were used. P. rufum fruit is smooth, shiny, hairless, with a red-purple color when ripe, so globosa, fleshy and indehiscent type bacoide. The seeds are campylotropous, reniform, with smooth, opaque and stony seed coat, and presented a possible endospermatic tissue and linseed in cream coloring. The embryo is of the pimentoide type and germination is epigeous phanerocotyledonal, starting on day 15 and extending to day 37 . The morphological characteristics presented are useful in helping identify P. rufum.
\end{abstract}

Keywords: Araçá-roxo, germination epigeous phanerocotyledonal

\section{INTRODUÇÃO}

Psidium rufum DC. é uma das 4000 espécies que compõem a família Myrtaceae (Souza \& Lorenzi 2008). É uma frutífera não cultivada, porém, ainda encontrada na natureza em seu habitat natural (Lorenzi et al. 2006). Além disso, é endêmica do Brasil (Sobral et al. 2014), podendo ser utilizada na restauração de áreas degradadas (Santos 2011), na arborização urbana e para consumo in natura de seus frutos (Lorenzi 2009).

A importância dos estudos morfológicos resulta, em grande parte, do fato do seu conhecimento estar na base da identificação das espécies. Segundo Kuniyoshi (1983), a grande dificuldade para estudos de estrutura, fenologia e comportamento de uma espécie dentro de uma comunidade é a sua identidade. Em determinadas circunstâncias, têmse apenas o fruto, a semente ou a plântula para o seu reconhecimento. O conhecimento morfológico de frutos, sementes e plântulas de Myrtaceae é notavelmente escasso, face ao elevado número de espécies nativas e à importância florestal e ecológica das mesmas.
De acordo com Souza \& Lorenzi (2008) esta é uma das mais complexas famílias da flora brasileira do ponto de vista taxonômico. Tal complexidade resulta não apenas do tamanho da família e da grande semelhança morfológica entre os diferentes gêneros e espécies, mas, principalmente, da falta de estudos taxonômicos mais abrangentes e da adoção de caracteres morfológicos considerados críticos para a sua delimitação (Schultz 1984, Barroso 1991, Landrum \& Kawasaki 1997).

A caracterização da morfologia de fruto, semente e plântula apresenta-se como alternativa para auxiliar na resolução dessas questões. Conforme preconizou Amorim (1996), o intuito de obter maior conhecimento sobre esses caracteres morfológicos, além de fornecer informações relativas à identificação e diferenciação de espécies, também auxilia nos laboratórios de análise de sementes, no reconhecimento da planta no campo, na taxonomia e na silvicultura.

Alguns trabalhos contribuíram na caracterização de aspectos morfológicos de espécies da família Myrtaceae, salientando-se os trabalhos de Kuniyoshi (1983) que dentre 
outras espécies caracterizou morfologicamente os frutos, sementes, germinação e plântulas de Myrcia arborescens $\mathrm{O}$. Berg, Oliveira \& Pereira (1984) que estudaram a morfologia das fases da germinação de Eugenia caryophyllata Thunb., Eugenia edulis Vell., Eugenia involucrata DC., Eugenia selloi (O. Berg) B.D. Jacks., Syzygium aqueum (Burm. f.) Alston, Syzygium jambos (L.) Alston e Syzygium malaccense (L.) Merr. \& L.M. Perry e Amorim (1996), que dentre outras espécies caracterizou morfologicamente os frutos, sementes, germinação e plântulas de Syzygium jambolanum (Lam.) DC. Além desses trabalhos, salientase também o de Santos et al. 2004) que descreveram os tipos de frutos e a germinação de Acca sellowiana (O. Berg) Burret, Campomanesia guazumifolia (Cambess.) O. Berg, Campomanesia xanthocarpa Mart. ex O. Berg, Eugenia rostrifolia D. Legrand, Myrcianthes pungens (O. Berg) D. Legrand e Psidium cattleyanum Sabine; Rego (2008) que estudou a germinação, morfologia e sanidade de sementes de Blepharocalyx salicifolius (Kunth) O. Berg e Myrceugenia gertii Landrum; Rego et al. (2011) que averiguaram a caracterização morfológica germinação de Curitiba prismatica (D. Legrand) Salywon \& Landrum; e Rodrigues (2012) que observou aspectos morfológicos de frutos, sementes e plântulas de Eugenia umbelliflora O. Berg.

Portanto, o objetivo do presente estudo foi descrever e ilustrar a morfologia de fruto, semente e plântula de $P$. rufum com o propósito de auxiliar no reconhecimento da espécie e contribuir nas mais diversas áreas como a taxonomia e a silvicultura.

\section{MATERIAL E MÉTODOS}

Os frutos foram coletados nos meses de maio e julho de 2014, de 11 árvores matrizes localizadas nos municípios de Curitiba (Parque São Lourenço) e Ponta Grossa (RPPN Meia Lua), Paraná. Após a coleta e o transporte, parte dos frutos foi utilizada para a sua caracterização morfológica e a outra foi macerada manualmente para a extração das sementes.

A caracterização morfológica dos frutos e das sementes de P. rufum foi realizada no Laboratório de Sementes Florestais do Departamento de Ciências Florestais da Universidade Federal do Paraná. Para descrever e ilustrar morfologicamente os frutos e as sementes foram utilizadas 100 unidades de cada um aleatoriamente. As observações foram feitas com lupa de mesa estereoscópica e a olho nu. As medidas de comprimento, largura e espessura das sementes foram estimadas, com auxílio de um paquímetro digital e expressas em milímetro. A média, o desvio padrão, o coeficiente de variação e os valores mínimo e máximo foram calculados no programa Microsoft Excel 2007. Além disso, cada medida da semente foi distribuída em classes de freqüência. Também foram obtidas as medidas de comprimento e largura de 100 frutos no Laboratório de Propagação de Espécies Nativas da Sociedade Chauá, assim como a massa fresca e o número de sementes por fruto.
Para a descrição dos frutos foram observados caracteres externos e internos do pericarpo, apenas no sentido topográfico e não ontogenético (Souza 2006), quanto à textura, consistência, pilosidade, brilho, forma, número de sementes por fruto e deiscência. Para a descrição das sementes foram observadas a posição do hilo e da micrópila e realizados cortes transversais e longitudinais para analisar as seguintes variáveis: cor, textura, consistência, forma, presença ou ausência de endosperma, e se presente o tipo e a cor deste. Ainda, foram observados o tipo, a forma e a posição do embrião, a forma e consistência dos cotilédones e a posição do eixo hipocótilo-radícula. Para o acompanhamento até a fase de plântula de $P$. rufum, 100 sementes foram colocadas em bandejas de plástico em substrato vermiculita. As ilustrações das fases, desde a emissão da radícula até o desenvolvimento dos eofilos foram executadas manualmente, ou seja, por meio de desenhos feitos à mão. A plântula foi considerada estabelecida quando os eofilos já estavam totalmente expandidos. A terminologia utilizada foi baseada nos trabalhos de Barroso et al. (1999), Kuniyoshi (1983) e Souza (2006, 2009).

\section{RESULTADOS}

Os frutos de Psidium rufum se caracterizam por serem carnosos e indeiscentes do tipo bacoide. A forma do fruto (Fig. 1A) é globosa, o epicarpo é liso, brilhante, glabro, com pouca espessura, de cor vermelho arroxeado quando maduro. O mesocarpo é semitransparente, carnoso e farto. Além disso, o fruto possui cálice pentâmero marcescente, de 1 a 7 sementes por fruto, sendo mais frequente 3 sementes por fruto. As dimensões, massa fresca e número de sementes por fruto são apresentados na Tabela 1 .

A semente (Figs. 1 D-G) é campilótropa, reniforme, com tegumento liso, opaco, pétreo, albuminosa (apresenta possível tecido endospermático), de cor creme e possui as seguintes dimensões: comprimento $(3,97 ; 5,49 ; 7,15 \mathrm{~mm})$, largura $(4,44 ; 5,60 ; 6,78 \mathrm{~mm})$ e espessura $(2,54 ; 3,95 ; 5,54$ $\mathrm{mm}$ ) (mínimo, média, máximo) (Tab. 2) distribuídas em classes conforme a Figura 2.

$\mathrm{O}$ embrião (Fig. $1 \mathrm{H}$ ) é do tipo hipocotilar, axial e pimentoide. Foi observado um possível tecido endospermático delgado, de cor creme, oleaginoso, envolvendo o embrião (Fig. 1 G). P. rufum apresenta hilo subapical em relação ao ápice da radícula, oval e monocromo. Próximo ao hilo é observado um orifício de forma irregular, onde internamente encontra-se a micrópila (Fig. 1 D).

O rompimento do tegumento ocorreu no $15^{\circ}$ dia após o início do acompanhamento se estendendo até o $37^{\circ}$ dia. $\mathrm{O}$ desenvolvimento da plântula se inicia com a abertura do opérculo e uma pequena expansão do eixo hipocótilo-radícula nessa região (Fig. 3 A). Apesar do opérculo não estar ilustrado, é uma estrutura que funciona como uma tampa na região da micrópila. Por volta do $3^{\circ}$ dia de germinação, a extremidade inferior do hipocótiloradicular sofre um afinamento progressivo dando forma a 


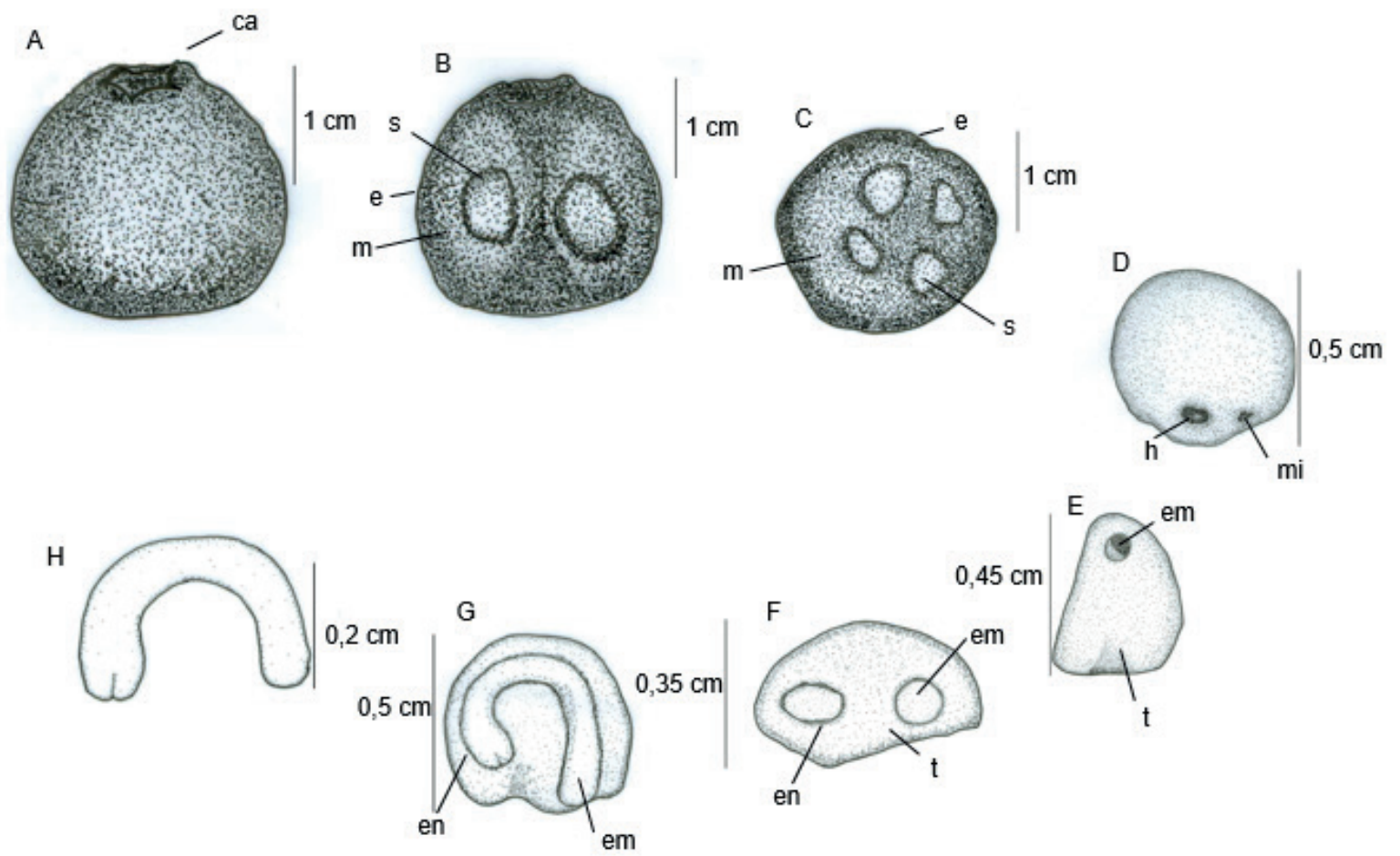

Figs. 1A-H. Morfologia do fruto e semente de P. rufum. A. fruto; B. secção longitudinal do fruto; C. secção transversal do fruto; D. semente; E. secção longitudinal da semente; F. secção transversal da semente; G. secção longitudinal da semente; H. embrião. ca. cálice; s. semente; e. epicarpo; m. mesocarpo; h. hilo; mi. micrópila; em. embrião; t. tegumento; en. endosperma.

Tabela 1. Dimensões do fruto, massa e número de sementes por fruto $P$. rufum

\begin{tabular}{lccccc}
\hline Dimensões $(\mathrm{mm})$ & Média & Desvio Padrão & CV (\%) & Mínimo & Máximo \\
\hline Comprimento & 15,94 & 2,11 & 13,23 & 11,47 & 20,31 \\
Largura & 16,84 & 2,74 & 16,29 & 9,77 & 22,89 \\
Massa fresca $(\mathrm{g})$ & 3,18 & 1,24 & 39,00 & 0,88 & 6,38 \\
$\mathrm{~N}^{\circ}$ de semente & 3,25 & 1,31 & 40,41 & 1 & 7 \\
\hline
\end{tabular}

Tabela 2. Valor médio, desvio padrão, coeficiente de variação (CV) e valor mínimo e máximo de características biométricas das sementes de P. rufum

\begin{tabular}{lccccc}
\hline Dimensões (mm) & Média & Desvio Padrão & CV (\%) & Mínimo & Máximo \\
\hline Comprimento & 5,49 & 0,67 & 12,18 & 3,97 & 7,15 \\
Largura & 5,60 & 0,56 & 10,00 & 4,44 & 6,78 \\
Espessura & 3,95 & 0,65 & 16,48 & 2,54 & 5,54 \\
\hline
\end{tabular}

radícula (Figs. $3 \mathrm{~B}, \mathrm{C})$. Após a ativação do "polo" radicial, a radícula torna-se densamente pilosa, de cor creme, levando a formação da raiz primária (Figs. $3 \mathrm{D}, \mathrm{E}$ ). O hipocótilo, inicialmente curvo, se expande elevando os cotilédones ainda presos ao tegumento. É visto também a formação das raízes secundárias (Fig. 3 F). A germinação é epígea e fanerocotiledonar.

Após o desprendimento dos cotilédones do tegumento por volta do $19^{\circ}$ dia de germinação (Fig. $3 \mathrm{G}$ ) ocorre a expansão dos mesmos, para que, na etapa subsequente apareça os eofilos (Fig. $3 \mathrm{H}$ ). Os cotilédones são foliáceos, de cor verde-clara, com margem inteira, nervuras pouco marcadas, superfície lisa, forma ovada, base aguda e ápice agudo. A raiz da plântula é axial, cilíndrica, sinuosa, de coloração castanho-claro. Inicialmente a plântula apresenta poucas raízes secundárias finas (Fig. $3 \mathrm{G}$ ). Os eofilos são opostos cruzados, simples, peciolados, membranáceos e elípticos, com margem inteira, ápice e base agudos, de acordo com a terminologia adotada por Souza (2009).

\section{DISCUSSÃO}

Visualmente, a coloração vermelho-arroxeada observada no epicarpo dos frutos é a alteração mais marcante que ocorre em $P$. rufum com o amadurecimento do fruto. As amplitudes observadas nas dimensões dos frutos, da massa fresca e número de sementes como vistos na Tabela 1 são decorrentes provavelmente, do fato de que 
A

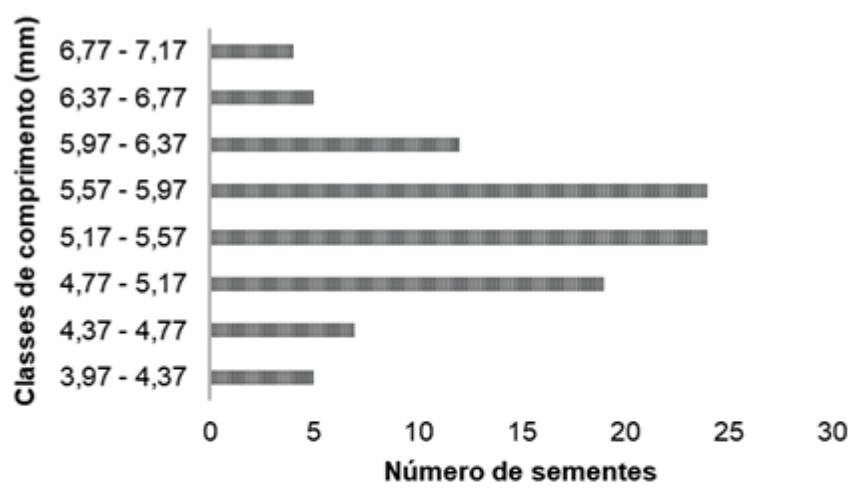

B

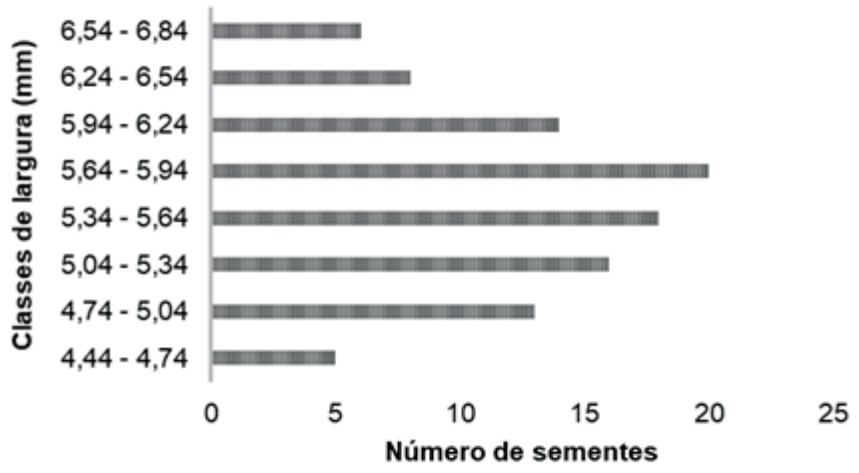

C

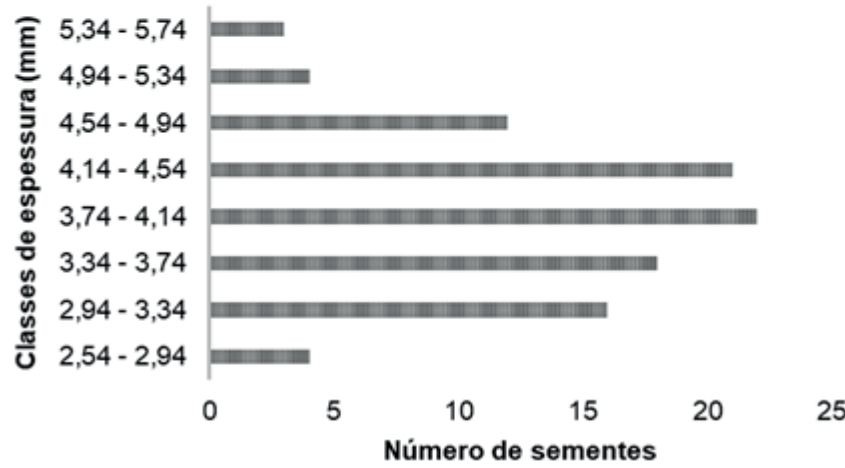

Figs. 2A-C. Classes de comprimento, largura e espessura de sementes de P. rufum

são oriundos de diferentes plantas-mães (Villachica et al. 1996, Carvalho \& Muller 2005) e da segregação causada pela alogamia, comum nas árvores frutíferas (Carvalho et al. 2003). Grande variabilidade na biometria também foi observada com os frutos de Eugenia calycina Cambess., que apresentaram amplitudes de 8-21 mm de largura e 10-30 $\mathrm{mm}$ de comprimento (Borges et al. 2010). Variações nas medidas de massa e tamanho dos frutos revelam o potencial de uma espécie frutífera para seleção e melhoramento genético (Fenner 1993).
Barroso et al. (1999) faz referências a frutos de Myrtaceae, como os "araçás do mato", que ainda não são aproveitados comercialmente e continuam à espera de estudos aplicados para serem consumidos num país carente de vitaminas. No entanto, é importante ressaltar que $P$. rufum possui sabor amargo, não recomendado para consumo humano, porém não impedindo seu uso para fins de pesquisa relacionados. Além disso, segundo Lorenzi (2009) os frutos de P. rufum são laxativos, mas são bem consumidos por pássaros. 

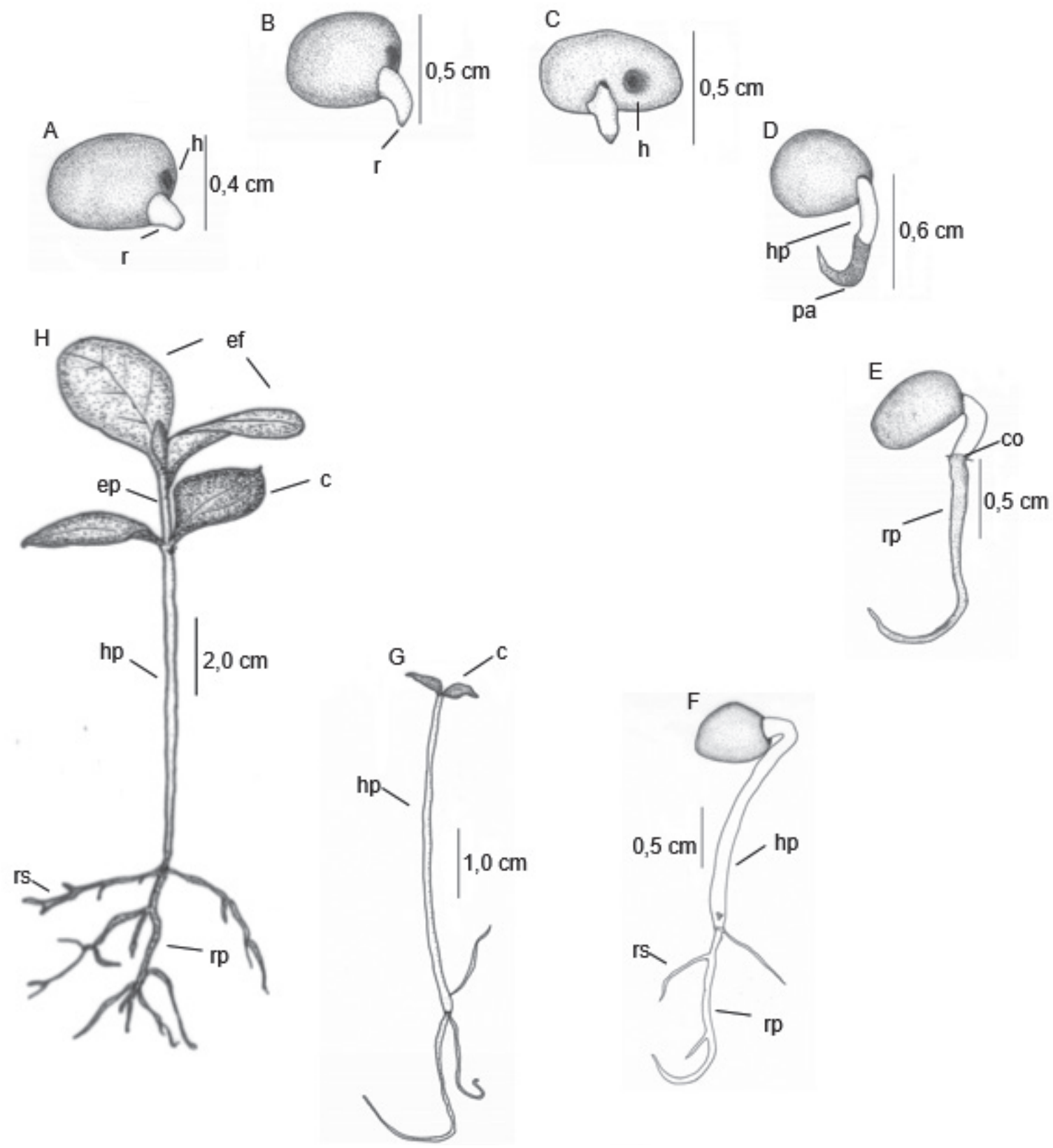

Figs. 3A-H. Fases da germinação e plântula de P. rufum. A. emissão da radícula; B. afinamento na região da radícula; C. vista frontal da semente; D. alongamento do hipocótilo e da raiz primária; E. alongamento da raiz primária; F. alongamento do hipocótilo e desenvolvimento da raiz; G. plântula; H. plântula com eofilos. h. hilo; r. radícula; hp. hipocótilo; pa. pelos absorventes; co. região do colo; rp. raiz primária; rs. raiz secundária; c. cotilédone; ep. epicótilo; ef. eofilos.

De acordo com a Figura 2 A é possível observar uma distribuição simétrica para as classes de frequência do comprimento das sementes, sendo que para as demais medidas houve uma maior variação na distribuição (Figs. 2 B, C). Ao comparar a semente de $P$. rufum com a de $P$. cattleyanum, descrita por Silva (2009), nota-se que possuem características em comum, pois ambas são campilótropas, reniformes e apresentam tegumento pétreo. Sobre o tegumento pétreo, Barroso et al. (1999) afirmam que esta é uma das características que permite a identificação do gênero Psidium L.
A classificação dada ao embrião de $P$. rufum também foi constatada nos trabalhos de Gogosz (2013) e Rego et al. (2011), no qual verificaram o embrião do tipo pimentoide para as mirtáceas $P$. cattleyanum e Curitiba prismatica. O hilo e a micrópila nas sementes da espécie são visíveis a olho nu (Fig. 1 D) e, segundo Marcos Filho (2005) são consideradas as principais áreas de entrada de água nas sementes. Cardoso (2004) também constata que a região hilar é considerada uma válvula higroscópica em sementes que apresentam tegumento impermeável, auxiliando na entrada de água para o interior da semente. 
Em virtude do tempo decorrido para a germinação do araçá-roxo neste trabalho, a germinação foi considerada rápida segundo $\mathrm{Ng}$ (1978). De acordo com este autor, uma germinação rápida de todas as sementes viáveis em um curto período de tempo é uma estratégia bem-sucedida, mas ineficaz, pois as plântulas irão competir entre elas. Estas espécies estarão mais vulneráveis à extinção, pois são mais suscetíveis ao ataque de predadores e não possuem um estoque de sementes no solo.

Em relação à disposição dos eofilos de P. rufum, Gogosz et al. (2010) também observaram na fase de desenvolvimento do primeiro par de eofilos de Campomanesia xanthocarpa, a filotaxia oposta cruzada, finalizando o estágio de plântula. Em relação a morfologia dos eofilos, Gomes et al. (2015) constataram em P. cattleyanum, eofilos elípticos, membranáceos e com margens inteiras, além de observar que a plântula da espécie apresentou sistema radicial axial e cilíndrica, corroborando com os resultados encontrados para $P$. rufum.

O caráter epígeo e a fanerocotiledonia em P. rufum também foram constatados por Gogosz et al. (2010), Pimenta et al. (2013), Haliski et al. (2013), Bassaco et al. (2014) e Gomes et al. (2015) onde averiguaram que a germinação é epígea e fanerocotiledonar em Campomanesia xanthocarpa., Annona crassiflora Mart., Casearia decandra Jacq., Sebastiania brasiliensis Spreng., P. cattleyanum e A. sellowiana. Na maioria dos casos, o caráter epígeo está associado a fanerocotiledonia e o hipógeo, à criptocotiledonia (Beltrati \& Paoli 2006).

O tipo de desenvolvimento da plântula (fanerocotiledonar e epígea), bem como a morfologia dos cotilédones de $P$. rufum (foliáceos) parecem estar relacionados com o estágio sucessional da espécie. Conforme preconizou Ressel et al. (2004), plantas clímax tardias têm sementes preponderantemente cripto-hipógeo-armazenadoras, que exibem maior capacidade de armazenamento e proteção durante o processo de germinação e estabelecimento, enquanto que, sementes de plantas pioneiras ou secundárias iniciais são frequentemente fanero-epígeo-foliáceas e resultam em plântulas como as de $P$. rufum, com cotilédones expostos e fotossintetizantes, que rapidamente assumem a função de nutrir a plântula em desenvolvimento. A classificação dada por Santos (2011) para P. rufum considerando-a como secundária inicial corrobora com as características apresentadas pela plântula da espécie. As características morfológicas apresentadas do fruto, semente e plântula de $P$. rufum são informações úteis e norteadoras para auxiliar no reconhecimento da espécie, em laboratórios de sementes ou outros fins. Nesse aspecto, as ilustrações também constituem um recurso valioso para uma análise comparativa.

\section{REFERÊNCIAS}

Amorim, I.L. 1996. Morfologia de frutos, sementes, germinação, plântulas e mudas de espécies florestais da região de Lavras - MG. Dissertação 127 f., Universidade Federal de Lavras, Minas Gerais.
Barroso, G.M. 1991. Sistemática de Angiospermas do Brasil. Universidade Federal de Viçosa, Viçosa. 377 p.

Barroso, G.M., Morim, M.P., Peixoto, A.L. \& Ichaso, C.L.F. 1999. Frutos e Sementes. Morfologia Aplicada à Sistemática de Dicotiledôneas. Universidade Federal de Viçosa, Viçosa. 443 p.

Bassaco, M.V.M., Nogueira, A.C. \& Cosmo, N.L. 2014. Avaliação da germinação em diferentes temperaturas e substratos e morfologia do fruto, semente e plântula de Sebastiania brasiliensis. Floresta 44(3):381-392.

Beltrati, C.M. \& Paoli, A.A.S. 2006. Semente. In Anatomia vegetal (B.A. Glória \& S. M.C. Guerreiro, eds.). Universidade Federal de Viçosa, Viçosa, p.399-414.

Borges, K.C.F, Santana, D.G., Melo, B. \& Santos, C.M. 2010. Rendimento de polpa e morfometria de frutos e sementes de pitangueira-docerrado. Revista Brasileira de Fruticultura 32(2):471-478.

Cardoso, V.J.M. 2004. Dormência: estabelecimento do processo. In Germinação: do básico ao aplicado (A.G. Ferreira \& F. Borghetti, eds.). Artmed, Porto Alegre, p. 95-108.

Carvalho, J.E.U. \& Muller, C.H. 2005. Caracterização física de frutos de matrizes selecionadas de bacurizeiro. In Anais do XIX Congresso Brasileiro de Fruticultura. Anais da Sociedade Brasileira de Fruticultura, Cabo Frio. p. 379.

Carvalho, J.E.U., Nazaré, R.F.R. \& Nascimento, W.M.O. 2003. Características físicas e físico-químicas de um tipo de bacuri (Platonia insignis Mart.) com rendimento industrial superior. Revista Brasileira de Fruticultura 25(2):326-328

Fenner, M. 1993. Seed ecology. Chapman \& Hall, London. 151p.

Gogosz, A.M. 2013. Morfologia funcional de plântulas como indicador fisionômico da dinâmica de regeneração de espécies arbóreas da Floresta Ombrófila Mista, Paraná. Tese 93 f., Universidade Federal do Paraná, Curitiba.

Gogosz, A.M., Cosmo, N.L., Bona, C. \& Souza, L.A. 2010. Morfoanatomia da plântula de Campomanesia xanthocarpa O. Berg. (Myrtaceae). Acta Botanica Brasilica 24(3):613-623.

Gomes, J.P., Oliveira, L.M., França, C.S.S., Dacoregio, H.M. \& Bortoluzzi, R.L.C. 2015. Caracterização morfológica de plântulas durante a germinação de sementes de Psidium cattleyanum e Acca sellowiana (Myrtaceae). Ciência Florestal 25(4):1035-1042.

Haliski, S.L., Cosmo, N.L., Gogosz, A.M., Rego, S.S., Nogueira, A.C. \& Kuniyoshi, Y.S. 2013. Caracterização morfológica de frutos, sementes, plântulas e germinação de sementes de Casearia decandra. Pesquisa Florestal Brasileira 33(75):253-259.

Kuniyoshi, Y.S. 1983. Morfologia da semente e da germinação de 25 espécies arbóreas de uma Floresta com Araucária. Dissertação 233 f., Universidade Federal do Paraná, Curitiba.

Landrum, L.R. \& Kawasaki, M.L. 1997. The genera of Myrtaceae in Brasil: an illustrated synoptic treatment and identification keys. Brittonia 49(4):508-536.

Lorenzi, H. 2009. Árvores Brasileiras: manual de identificação e cultivo de plantas arbóreas nativas do Brasil. Plantarum, Nova Odessa. 384 p.

Lorenzi, H., Bacher, L., Lacerda, M. \& Sartori, S. 2006. Frutas brasileiras e exóticas cultivadas: de consumo in natura. Instituto Plantarum de Estudos da Flora, São Paulo. 627 p.

Marcos Filho, J. 2005. Fisiologia de sementes de plantas cultivadas. Fundação de Estudos Agrários Luiz de Queiroz, Piracicaba. 495 p.

Ng, F.S.P. 1978. Strategies of establishment in Malayan forest trees. In Tropical trees as living systems (P.B.P. Tomlinson \& M.H. Zimmermann, eds.). Cambridge University Press, Cambridge, $p$. 129-162.

Oliveira, E.C. \& Pereira, T.S. 1984. Myrtaceae-Morfologia da germinação de algumas espécies. In Congresso Nacional de Botânica. Sociedade Botânica do Brasil, Porto Alegre, p. 501-520.

Pimenta, A.C., Rego, S.S., Zuffellato-Ribas, K.C., Nogueira, A.C. \& Koehler, H.S. 2013. Morphological characterization of fruits, seeds and seedlings of araticum plant (Annona crassiflora Mart Annonaceae). Journal of Seed Science 35(4):524-531.

Rego, S.S. 2008. Germinação, morfologia e sanidade de sementes de Blepharocalyx salicifolius (H.B.K.) Berg e Myrceugenia gertii Landrum - Myrtaceae. Dissertação 113 f., Universidade Federal 
do Paraná, Curitiba.

Rego, S.S., Cosmo, N.L., Gogosz, A.M., Kuniyoshi, Y.S. \& Nogueira, A.C. 2011. Caracterização morfológica e germinação de sementes de Curitiba prismatica (D. Legrand). Revista Brasileira de Sementes 33(4):616-625.

Ressel, K., Guilherme, F.A.G., Schiavini, I. \& Oliveira, P.E. 2004. Ecologia morfofuncional de plântulas de espécies arbóreas da Estação Ecológica do Panga, Uberlândia, Minas Gerais. Revista Brasileira de Botânica 27(2):311-323.

Rodrigues, M.A. 2012. Ecofisiologia e aspectos morfológicos de frutos, sementes e plântulas de Alchornea triplinervia (Spreng.) M. Arg. (Euphorbiaceae) e Eugenia umbeliflora O. Berg. (Myrtaceae). Tese 177 f., Universidade Estadual Paulista, Rio Claro.

Santos, M.B. 2011. Enriquecimento de uma floresta em restauração através da transferência de plântulas da regeneração natural e da introdução de plântulas e mudas. Tese 115 f., Escola Superior de Agricultura Luiz de Queiroz, Universidade de São Paulo, Piracicaba.

Santos, C.M.R.; Ferreira, A.G. \& Áquila, M.E.A. 2004. Características de frutos e germinação de sementes de seis espécies de Myrtaceae nativas do Rio Grande do Sul. Ciência Florestal 14(2):13-20.
Schultz, A.R.H. 1984. Introdução à Botânica Sistemática. Universidade Federal do Rio Grande do Sul, Porto Alegre. 414 p.

Silva, A. 2009. Morfologia, conservação e ecofisiologia da germinação de sementes de Psidium cattleyanum Sabine. Tese 179 f., Universidade Federal de São Carlos, São Carlos.

Sobral, M., Proença, C., Souza, M., Mazine, F. \& Lucas, E. 2014. Myrtaceae. Lista de Espécies da Flora do Brasil. Disponível em: http://floradobrasil.jbrj.gov.br/jabot/floradobrasil/FB10883. Acessado em 05.07.2014.

Souza, L.A. 2006. Anatomia do fruto e da semente. Universidade Estadual de Ponta Grossa, Ponta Grossa. 200 p.

2009. Morfologia e anatomia vegetal: célula, tecidos, órgãos e plântula. Universidade Estadual de Ponta Grossa, Ponta Grossa. 259 p.

Souza, V.C. \& Lorenzi, H. 2008. Botânica Sistemática - Guia ilustrado para a identificação das famílias de fanerógamas nativas e exóticas no Brasil, baseado em APG II. Nova Odessa, Plantarum. 768 p.

Villachica, H., Carvalho, J.E.U., Müller, C.H., Diaz, S.C. \& Almanza, M. 1996. Frutales y hortalizas promissorios de la Amazonia. Tratado de Cooperacion Amazonica 44(1):152-156. 
